\title{
WAVE TRANSFORMATION AND WAVE-DRIVEN CIRCULATION ON NATURAL REEFS UNDER EXTREME HURRICANE CONDITIONS
}

\author{
Ismael Mariño-Tapia ${ }^{1}$, Rodolfo Silva-Casarín ${ }^{2}$, Cecilia Enriquez-Ortiz ${ }^{1}$, Edgar Mendoza- \\ Baldwin $^{2}$, Edgar Escalante Mancera ${ }^{3}$, Francisco Ruiz-Rentería ${ }^{3}$
}

\begin{abstract}
The understanding of wave transformation and circulation on coral reef environments has profound implications for the preservation of the natural environment and also for the planning of mitigation measures which protect the coastline. Most of the Mexican Caribbean coast is fronted by reefs, and it is here where coastal development is being undertaken at an alarming rate, as tourist resorts expand and multiply. The transport and dispersion of larvae (fish and coral), nutrients, pollutants, heat, and sediments are dictated mainly by circulation processes which are, to a great extent, dominated by wave processes at fringing reefs. Wave transformation on coral reefs has received considerable attention, but the 2D effects of wave reflection and diffraction have not often been addressed despite the complex geometry and steep foreshores that characterize fringing reefs. In this contribution the effects of reflection and diffraction are explored by the application of a model that considers these two processes (WAPO/COCO) and another that does not (SWAN/DELFT3D), at Puerto Morelos on the Mexican Caribbean coast. Reanalysis data of 48 years of wave parameters show that waves of $2 \mathrm{~m}$ height can be considered as high energy storm conditions, which are generated mainly by passing hurricanes and to a lesser extent by northerly storms in winter. These are the conditions used to run the models using a range of wave periods $(8,10$ and 12 seconds) and directions (SE, NE and NNE). The results show that the reflection-solving model is able to generate rhythmic patterns in the horizontal distribution of Hs that are not reproduced by the SWAN model. Furthermore, the patterns change considerably depending on wave period and direction. These differences are attributed to the effects of full diffraction and reflection processes. While both models perform well and reproduce previously reported circulation patterns, the differences in Hs horizontal distribution generated by the WAPO model have important implications for the circulation around the reef crests. For instance, vorticity is increased and in many occasions a different pattern from that suggested by SWAN occurs, such as a clear southward longshore current along the reef crest under northerly wave forcing. Although the circulation was calculated in both models by the same method (radiation stress gradients), the version of COCO which was used generates smaller set-up inside the reef lagoon and therefore the circulation in this region and at the outlets is underestimated. Although it is necessary to corroborate the model results with measurements of the 2D wave height patterns and circulation, the magnitude of the currents suggested by the reflection-solving model are strong enough to persist even under the presence of stronger flows inside the lagoon and at the inlets due to wave set-up gradients.
\end{abstract}

Keywords: wave-driven circulation; coral reefs; wave diffraction and reflection.

\section{INTRODUCTION}

\section{Motivation for the study}

The understanding of oceanographic processes enhances the possibility of maintaining environmental integrity in coastal zones, which is crucial for the preservation of human activities and ultimately for the promotion of sustainable development along coastlines.

Due to the existence of highly porous and permeable karst rocks, the Yucatan peninsula, in eastern Mexico, lacks surface rivers. This promotes the existence of a vast network of underground waterways that carry fresh water to the ocean. Any inland activity that improperly disposes wastewater to the underground, will be contributing to the pollution and eutrophication of the coastal zone. Coral reefs are extremely sensitive to excess nutrients and can easily perish if eutrophication occurs, giving rise to 'stage shifts' where coral and fish species are displaced by algae, thus affecting the environmental balance and degrading the reef systems.

On the other hand, coral reef degradation has important implications for coastal protection as a dead reef would be easily eroded, losing its morphological complexity, hence diminishing friction and thereby lessening its capacity to protect the coast efficiently. Shoreline dynamics extracted from satellite images (2006 - 2009) show that beaches without protection from natural reefs (i.e. Cancun)

${ }^{1}$ Departamento de Recursos del Mar, Cinvestav, Km 6 Carretera Antigua a Progreso, Cordemex, 97310, A.P. 73, Mérida, Yuc., Mexico.

${ }^{2}$ Instituto de Ingeniería, UNAM, Circuito Universitario s/n, Ciudad Universitaria, Mexico, D.F.

${ }^{3}$ Instituto de Ciencias del Mar y Limnología, UNAM, Unidad Académica Puerto Morelos, Quintana Roo, Mexico. 
loose sand at a rate of $20 \mathrm{my}^{-1}$, whereas beaches that are fronted by reefs loose sand at a rate of only 5 $\mathrm{my}^{-1}$ (Martell, et al. 2010).
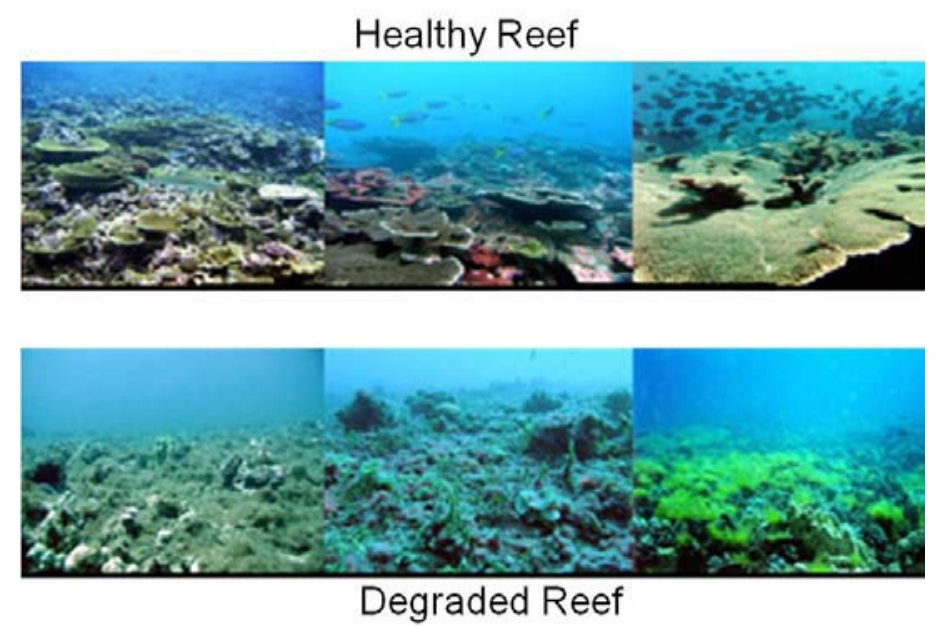

Figure 1. Examples of phase shifts from healthy reefs into algae-invaded reefs.

Furthermore, coral bleaching is associated with excess temperature. It would be expected that temperatures of the stagnant waters of a shallow reef lagoon would easily rise, inducing coral bleaching. Therefore, understanding circulation in coral reef environments has profound implications for the preservation of natural beaches (sediment transport) and for the environmental balance (pollutant and heat dispersion).

\section{Study site}

The reef lagoon is located at Puerto Morelos, Quintana Roo, on the northeastern corner of the Yucatán Peninsula, $30 \mathrm{~km}$ south of the famous tourist resort of Cancun, facing the Mexican Caribbean. The coast is fronted by a shallow $(\mathrm{z}<5 \mathrm{~m})$ fringing reef lagoon protected by fragmented reef crests where numerous groundwater springs discharge (Figure 2). These springs are a major source of nutrients and pollutants to the reef ecosystem, and their intensity is such that they modify density gradients affecting circulation locally through baroclinic effects. Offshore from the reef there is a rapid fall in the bathymetry and very strong along-shelf currents $(\sim 1.5 \mathrm{~m} / \mathrm{s})$. The site is part of the Mesoamerican Barrier Reef System where tourism is the main economic activity.

Wave measurements at bouy 42056 (NDBC-NOAA), located in the Caribbean basin at a water depth of 4,446 m, show that waves propagate predominantly from the Caribbean Sea (SSE direction) driven by the dominant winds, and a small percentage come from north, generated by the winter storms from the Gulf of Mexico. Ninety percent of the observations show a relatively small significant wave height $(<1 \mathrm{~m})$ and small wave periods $(<8 \mathrm{sec})$, which is an indication of locally generated seas. Reanalysis data, comprising 48 years of wave modeling (Silva, et. al. 2008), show that waves with Hs $\sim 2 \mathrm{~m}$ can be considered as high energy storm conditions, which are usually generated by passing hurricanes and to a lesser extent by northerly storms in winter. Tidal oscillations have a semidiurnal signal, with small amplitudes (spring tidal ranges of $0.4 \mathrm{~m}$ ), but sea level variations of atmospheric or geostrophic origin can alter significantly the sea level variability. These oscillations in sea level have profound implications for wave breaking on the reef tops (Coronado, et. al. 2007). 


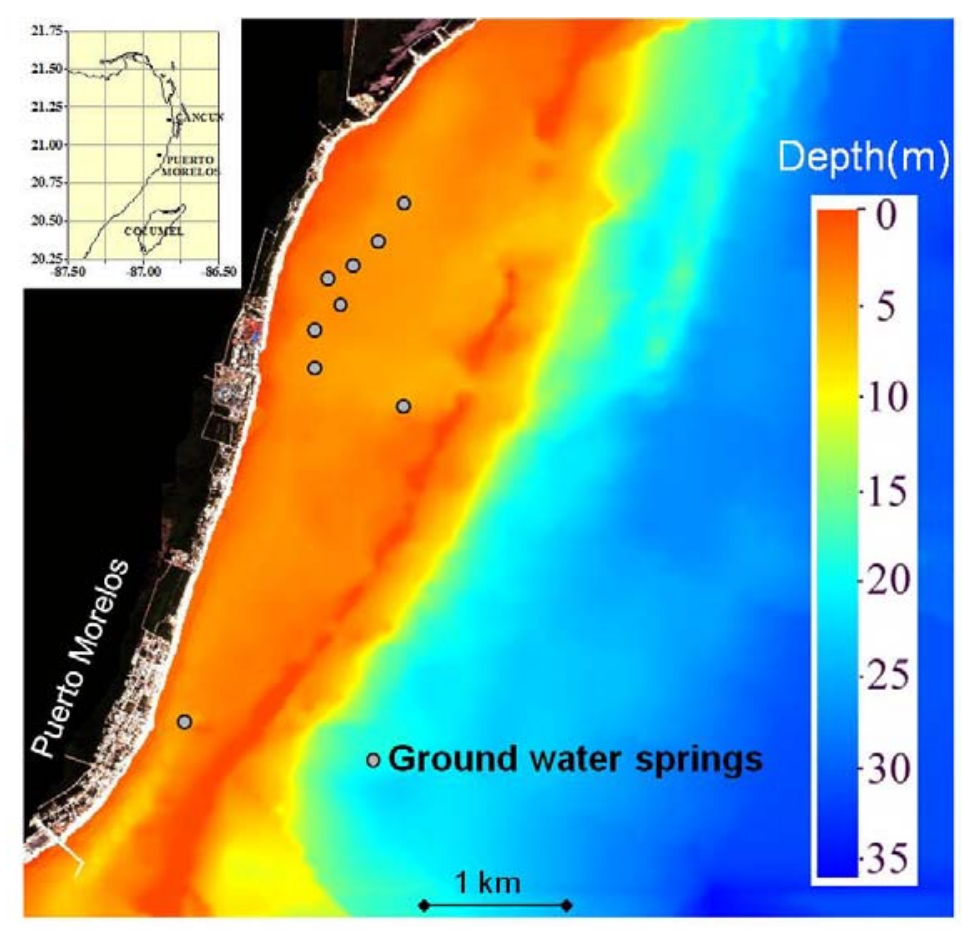

Figure 2. Bathymetry of the reef lagoon at Puerto Morelos showing the reef crests in red and the location of groundwater springs.

\section{CIRCULATION AROUND FRINGING REEFS AND THE PRESENT STUDY}

Although winds, tides and buoyancy effects can play an important role in the circulation around coral reefs, wave breaking has long been recognized as the dominant forcing mechanism within many wave-exposed reef systems (e.g., Angwenyi and Rydberg, 2005; Hench et al., 2008). This forcing is provided by wave breaking on the fore reef which causes a local increase in the mean sea level (wave setup) on the reef, establishing a pressure gradient that drives cross-reef mean flows.

Coronado, et. al. (2007), studied the circulation at the Puerto Morelos fringing reef using a set of four acoustic doppler profilers (Aquadop, Nortek), two located inside the reef lagoon (south and center), one at a reef opening, and another offshore at $20 \mathrm{~m}$ depth. The results of this investigation clearly show that currents inside the lagoon and in the reef openings have a preferential direction towards the exterior, whereas outside the lagoon, the main axis of variability is along the isobaths, but the mean current is directed onshore, consistent with wave generated stokes drift. In the northern and southern inlets, the mean current speed is $\sim 0.20 \mathrm{~ms}^{-1}$, reaching maximum values $\sim 1 \mathrm{~ms}^{-1}$, while inside the lagoon currents remain small with an average current speed of $\sim 0.10 \mathrm{~ms}^{-1}$, consistently directed to the north and with little tidal influence. The average vertical current profile is almost unidirectional. EOF analysis of the current data shows a high correlation between the temporal evolution of the subinertial first EOF mode and the significant wave height inside the lagoon $(r=0.9)$. This strongly suggests that waves govern the circulation for this fringing reef lagoon.

Most attempts to understand and predict wave-driven flows on reefs have used 1D analytical solutions or numerical models, assuming an idealized reef depth profile and utilizing simple wave transformation models to estimate maximum wave set-up due to radiation stress gradients in the surf zone (e.g. Gourlay and Colleter, 2005). Recently, Lowe, et al. (2009) applied a fully coupled wavecirculation model (DELFT3D - SWAN) to a morphologically complex reef system in Hawaii. The model was able to explain the behavior of in situ point measurements to reproduce wave set up gradients and circulation in this system, which is also governed by wave driven circulation. Despite this advance in the study of wave-driven reef circulation, most studies do not include the effects of 2D wave reflection and diffraction processes which should have profound effects on the spatial 
distribution of wave setup and, consequently, on the circulation patterns originated in these systems, as coral reefs have very steep seaward faces, as well as a complex morphology. The study of such processes and their effects on circulation is not possible with wave propagation models such as REFDIF, SWAN, etc. as diffraction and reflection processes are not solved by these models. However, using a second-order parabolic approximation, Silva et al. (2005) were able to develop a numerical wave propagation model (WAPO) capable of representing open, partially reflected and fully transmitting conditions for both incoming and outgoing waves. Therefore, this linear wave propagation model can solve implicitly refraction, reflection and diffraction. The model is robust and can be used in complex geometries and has fewer restrictions associated with wave obliqueness at boundaries than traditional models based on the mild-slope equation.

The present contribution assesses the importance of including wave reflection and diffraction on the estimation of wave-driven circulation in coral reef systems by comparing the results of a widely used 2D propagation model, SWAN, which cannot include these processes, and those obtained using a model which is capable of including them, WAPO. The mesh resolution for the WAPO model is $10 \mathrm{~m}$ and comprises an area of $6 \mathrm{~km}$ alongshore and $3 \mathrm{~km}$ in the cross-shore direction. This model is nested in a larger scale model where REFDIF was used to propagate waves from deep waters to the WAPO boundary. The SWAN model has a resolution of $20 \mathrm{~m}$ and comprises an area of $10 \mathrm{~km}$ alongshore and $6 \mathrm{~km}$ offshore up to depths of $60 \mathrm{~m}$. In SWAN, whitecapping dissipation, quad and triad interactions are switched off to make the results more compatible. The models were fed with conditions representative of high energy waves driven by mild storms. This includes $\mathrm{Hs}=2 \mathrm{~m}, \mathrm{Tp}=8-12 \mathrm{sec}$, and azimuth directions of $22.5^{\circ}, 45^{\circ}, 90^{\circ}$, and $135^{\circ}$, to reproduce the main storm directions. Using the output of these models, radiation stresses and wave driven currents are calculated using the COCO (Mendoza et al., 2008) and DELFT 3D hydrodynamic models respectively.

\section{EFFECTS OF DIFFRACTION AND REFLECTION ON WAVE HEIGHT AND CIRCULATION}

Figure 3 shows the comparison between the horizontal distribution of wave heights between the WAPO and SWAN models for the propagation of $2 \mathrm{~m}$ and 8 sec waves from SE $\left(135^{\circ}\right)$.
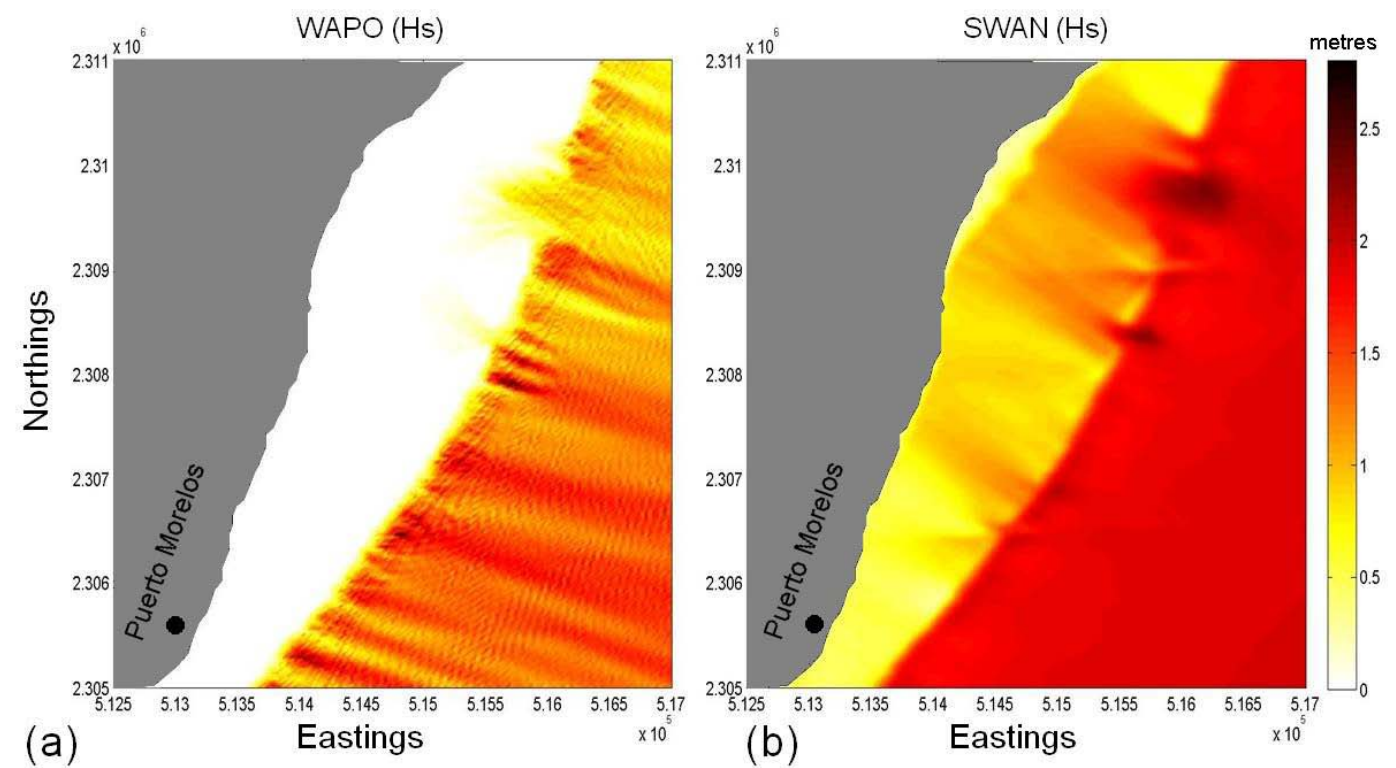

Figure 3. Results of wave propagation (Hs spatial distribution) with the WAPO model (a) and the SWAN model (b), for boundary conditions of $\mathrm{Hs}=2 \mathrm{~m}, \mathrm{Tp}=8 \mathrm{~s}, \theta=135^{\circ}$.

The SWAN model suggests a more uniform wave transformation pattern where waves lose height monotonically in most of the region with the exception of some segments at the reef openings, where wave heights increase and penetrate considerably inside the lagoon. The WAPO model on the other hand, suggests rhythmic resonant wave patterns around the reef and in the offshore region, due to the diffraction and reflection on the reef and the offshore bathymetry, with very small to null waves inside 
the lagoon. The sharp differences inside the lagoon might be explained by the fact that the WAPO model is monochromatic, whereas SWAN is spectral, hence, smaller and shorter waves might propagate closer to shore without dissipating their energy.

The most striking differences appear with changing wave period (i.e. 10 seconds, in Figure 4). Whilst SWAN preserves a very similar pattern of wave height distribution to that observed for $8 \mathrm{sec}$ waves, the WAPO model presents a different rhythmic pattern, and wave focusing occurs in different regions. In general waves tend to focus strongly on the northern opening of the reef crests and energy diverges on most of the reef tops to the south (lighter colors than Figure 3).
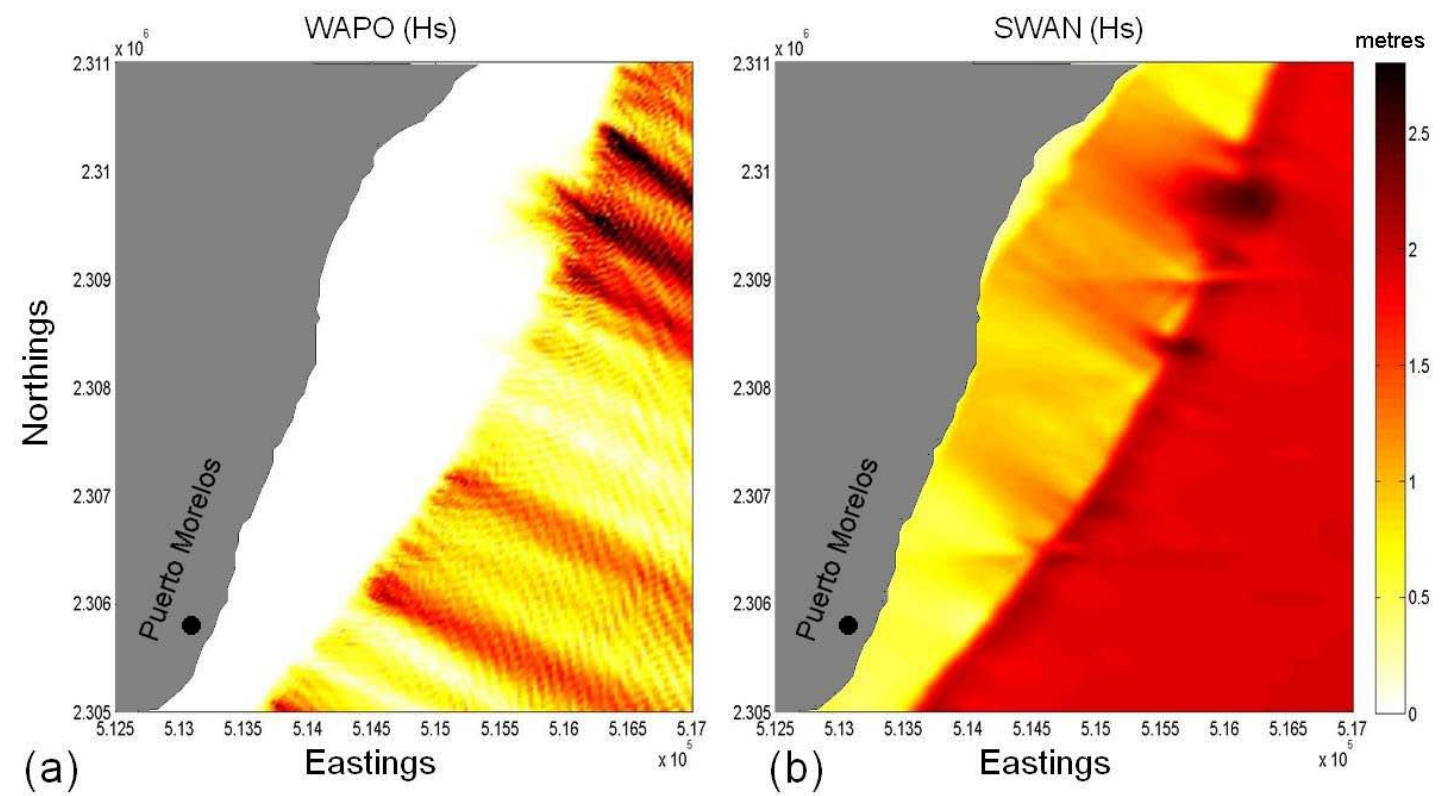

Figure 4. Results of wave propagation (Hs spatial distribution) with the WAPO model (a) and the SWAN model (b), for boundary conditions of $\mathrm{Hs}=2 \mathrm{~m}, \mathrm{Tp}=10 \mathrm{~s}, \theta=135^{\circ}$.

The sharp differences found in the spatial distribution of wave heights for both models should be reflected in the velocity field calculated from the radiation stresses. Figure 5 shows the results of the hydrodynamic models COCO and DELFT 3D for the output of WAPO and SWAN respectively.

For $\mathrm{Tp}=8 \mathrm{sec}$, and $\theta=135^{\circ}$, the velocity field shows many qualitative similarities between both models, i.e. there is a net outflow from the reef lagoon to the south and through the reef openings, especially through the larger ones in the north, small northward flows dominate inside the lagoon, and small onshore currents exist outside the reef. These elements coincide qualitatively with the velocity patterns measured by Coronado et al. (2007), giving certainty to the results of both models. This behavior occurs due to an increase in wave height spread along most of the reef crests, which generates large semi-uniform wave breaking and resulting in large set-up inside the reef lagoon. This general behavior is true even for the WAPO model which shows a marked rhythmicity of the above mentioned general pattern.

The output of models also shows important differences. DELFT 3D (Figure 5b) suggests stronger currents on both the outflow on the northern reef openings and the inflow (onshore flows) along the reef tops, which penetrate well inside the reef lagoon. This has important implications for the system, as under the above scenario, the water residence time should be small and the reef lagoon must have very active dynamics for energetic wave conditions. On the other hand the COCO model (Figure 5a) suggests that wave-driven circulation is more restricted to the reef tops and presents smaller scale vorticity with a less unidirectional onshore flow on the reef tops. This has important implications for the dispersion of coral larvae. Under this later scenario coral larvae should have more chance to settle in the reef crests, and not be dispersed inside the lagoon by the action of unidirectional onshore flows. 


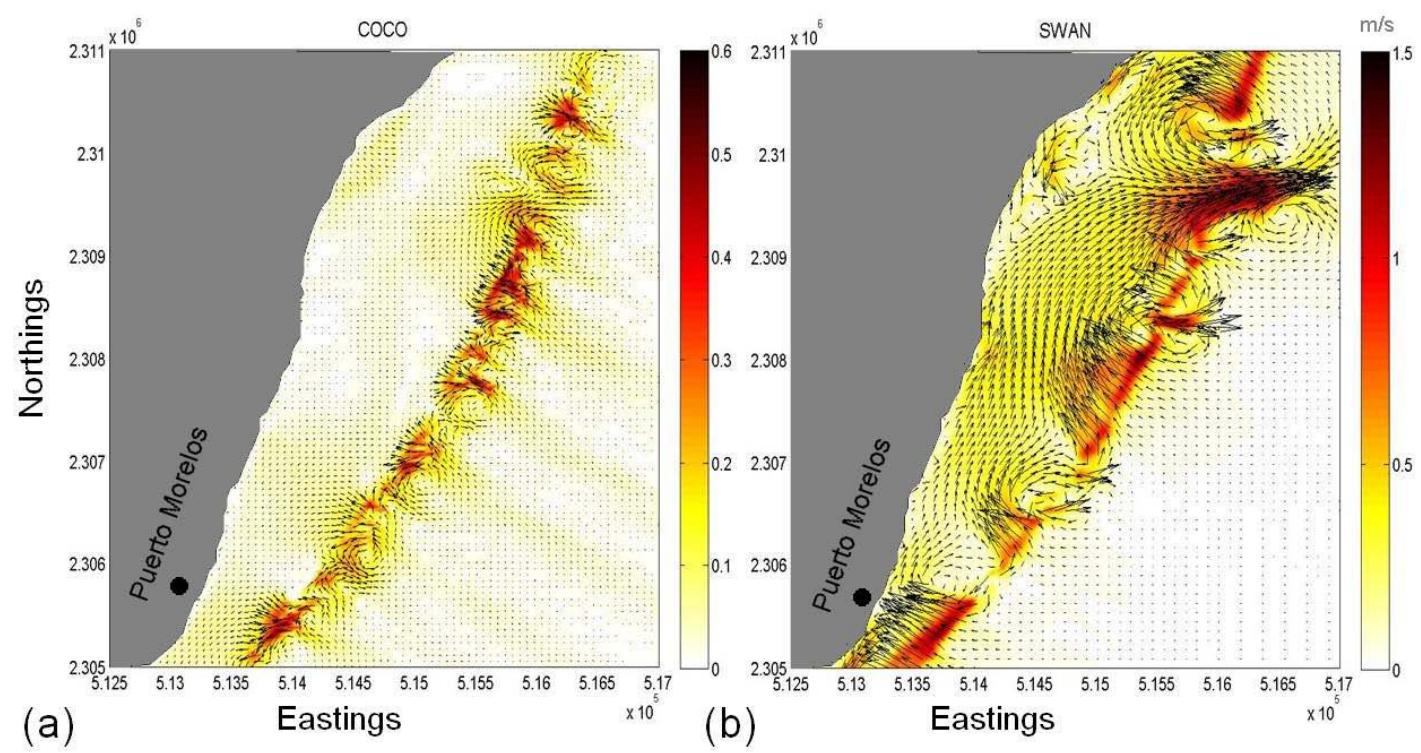

Figure 5. Results of the hydrodynamic models showing wave-driven flows for the reflection/diffraction model, COCO (a), and with DELFT3D (b), for boundary conditions of $\mathrm{Hs}=2 \mathrm{~m}, \mathrm{Tp}=8 \mathrm{~s}, \theta=135^{\circ}$. Colorbars in $\mathrm{m} / \mathrm{s}$.

If $\mathrm{Hs}$ and $\theta$ are maintained, but the wave period changes to $10 \mathrm{~s}$, the results of the circulation patterns remain the same for DELFT 3D with slightly larger magnitudes, but change drastically for the reflection/diffraction solving model (Figure 6).

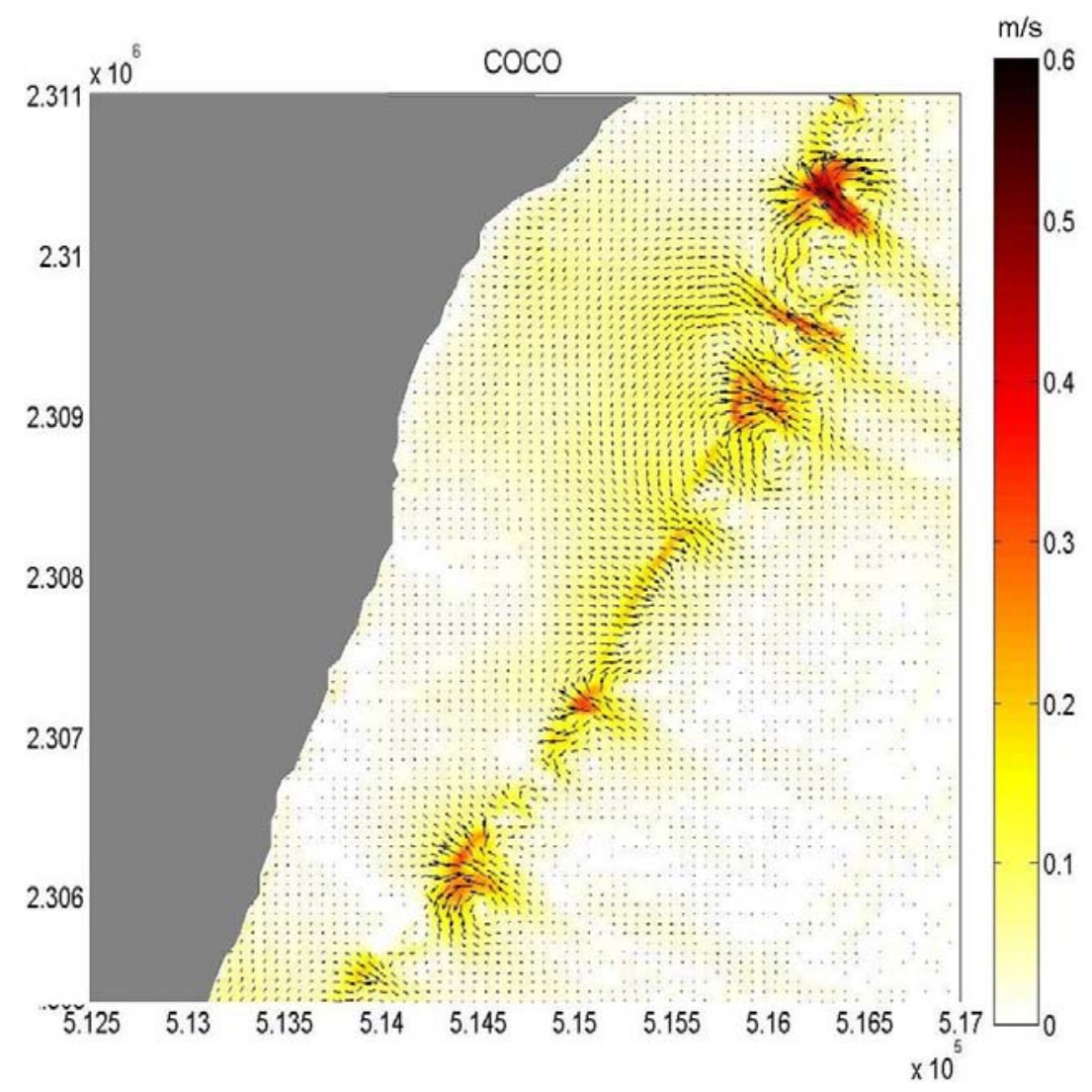

Figure 6. Wave-driven flows for the reflection/diffraction model, coco for boundary conditions of $\mathrm{Hs}=\mathbf{2}$ $\mathrm{m}, \mathrm{Tp}=10 \mathrm{~s}, \theta=135^{\circ}$. 
The effects of diffraction and reflection produce a net water flow into the lagoon through the northern reef opening, where Hs spatial gradients are strongest, and a flow out of the reef lagoon over the reef tops, located in the middle of the domain, which is, for this wave condition, a dissipative region of diminished wave heights (see Figure $4 \mathrm{a}$ ). These reduced wave heights generate smaller wave set up and therefore an outflow region. This pattern of circulation is radically different to that suggested by DELFT 3D, where the circulation pattern is invariant with respect to the wave conditions generated by $8 \mathrm{~s}$ waves. It is worth mentioning that this wave condition has a very low probability of occurrence $(<1 \%)$.

Similarly to what has been shown for wave period, DELFT 3D generates very similar (almost identical) circulation patterns for oblique wave angles from the NE quadrant $\left(22.5^{\circ}\right.$ and $\left.45^{\circ}\right)$, but the COCO model has important differences. Figure 7 shows the wave driven circulation for the COCO model using oblique northerly waves with $\mathrm{Hs}=2 \mathrm{~m}$ and $\mathrm{Tp}=10 \mathrm{~s}$.

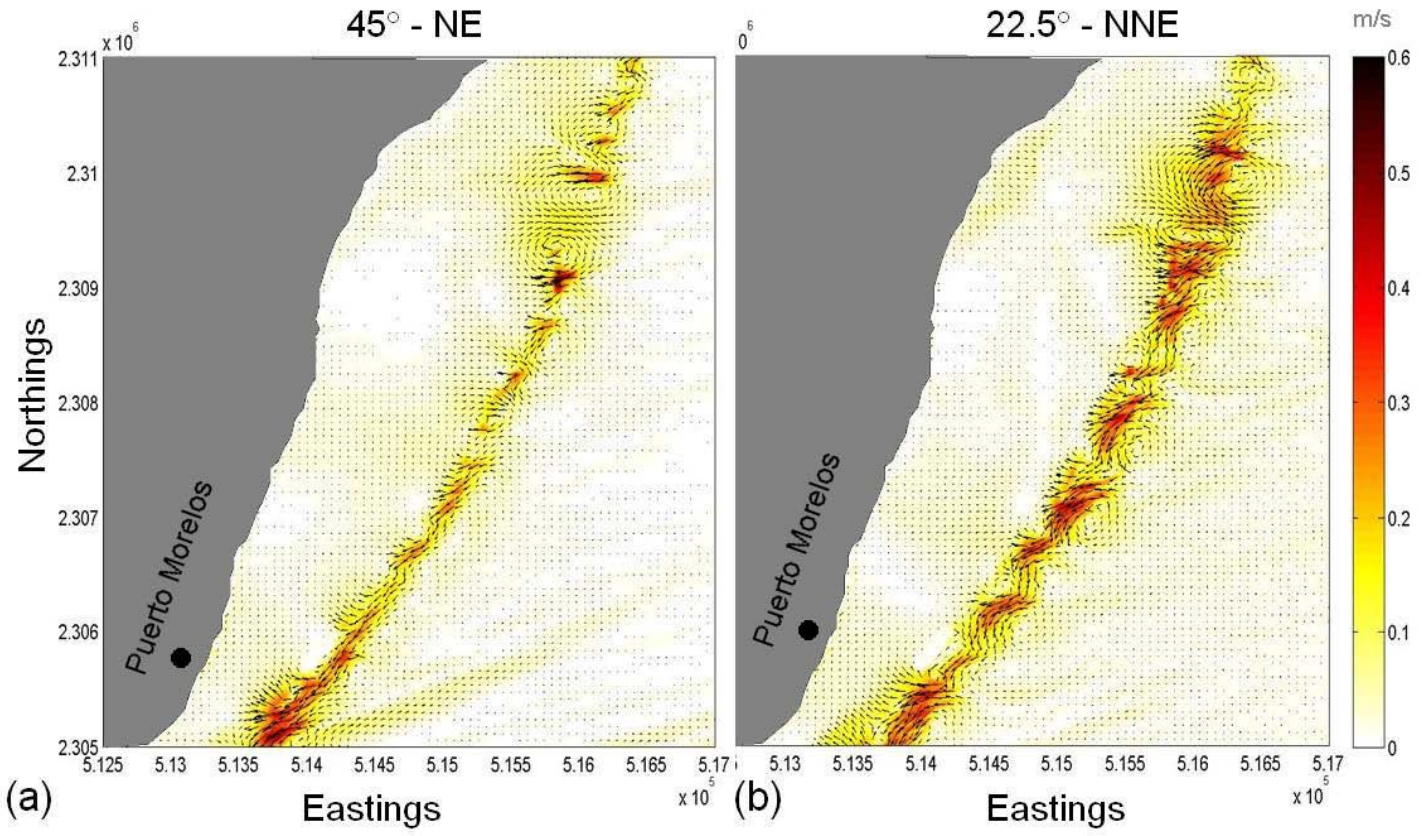

Figure 7. Wave-driven flows for the reflection/diffraction model, $\mathrm{COCO}$ for boundary conditions of $\mathrm{Hs}=2$ $\mathrm{m}, \mathrm{Tp}=10 \mathrm{~s}, \theta=45^{\circ}(\mathrm{a})$ and $22.5^{\circ}(\mathrm{b})$.

For both wave conditions, representative of northerly winter storms, the outflow circulation through the main reef opening in the north is reestablished despite the wave period is also $10 \mathrm{~s}$. Wave driven circulation is more restricted to an along reef southward flow with strong modulation and vorticity for the most oblique angle $\left(22.5^{\circ}\right)$. Inside the lagoon circulation is restricted.

The observations of invariant water flows predicted by DELFT 3D, regardless of wave period or oblique direction, is of concern, as one would expect larger differences. A possible cause for this persistence in the circulation could be an over estimation of set up inside the lagoon which would govern water movement by trying to alleviate the reef lagoon from excess water and thus overwhelm any other effect. An analysis of the set up gradients inside the reef lagoon confirms this hypothesis, and the results shed some light on the behavior of the velocity field as generated by the DELFT model (Figure 5b). Figure 6 shows the set up distribution (water level) for $\mathrm{Hs}=2 \mathrm{~m}$, Tp $=10 \mathrm{~s}$ and $\theta=135^{\circ}$.

Using water level measurements, Coronado et al. (2007) report differences between their offshore instrument and the one inside the lagoon of $\sim 5 \mathrm{~cm}$ for waves of Hs $=2 \mathrm{~m}$. DELFT 3D suggests that the water level difference is close to $14 \mathrm{~cm}$ (see Figure 8), which is a considerable over prediction. This could explain the invariance of the DELFT 3D results regarding the flow patterns, and the 
strength of the currents. An excess set up inside the lagoon will force water to move out of the reef lagoon generating the pattern observed on Figure $5 b$.

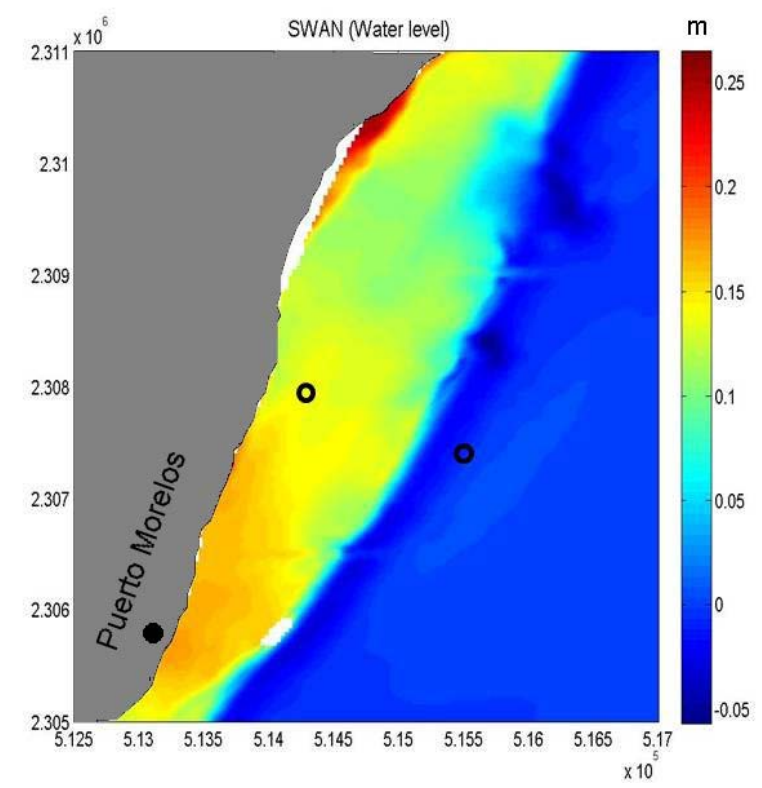

Figure 8. Wave set up generated with the DELFT3D model. Values in $\mathrm{cm}$. The round markers represent the approximate position of the instruments LPM1 and LPM3 installed by Coronado et al. (2007).

\section{SUMMARY OF FINDINGS}

Under conditions of dominant wave direction (SE $-135^{\circ}$ ), a pattern of circulation that coincides well with observations (Coronado et al. 2007) is reproduced by both models. This consists of a net outflow from the reef lagoon to the south and through reef openings, especially the larger ones in the north, as well as small northward flows inside the lagoon, in addition to small onshore currents outside the reef. DELFT 3D plus SWAN models suggest that these circulation patterns are persistent, regardless of direction or period. This might be a result of wave setup over prediction which will tend to produce an intense and constant outflow from the reef lagoon.

The reflection/diffraction solving model (WAPO/COCO) suggests that resonant patterns in Hs change drastically outside the reef with respect to wave period and direction. This can affect circulation considerably. The WAPO model predicts circulation to be more restricted to the reef tops and shows an increased small scale vorticity as compared to the more defined flows suggested by DELFT 3D. While the model is capable of incorporating wave set up, values are likely to be underpredicted, as velocity estimates are small as compared (qualitatively) with measurements.

The authors recognize that monochromatic wave conditions are very difficult to find in nature, and the results of the reflection/diffraction solving model might be altered if a wave spectrum is considered instead of a monochromatic wave condition. This could smooth the observed rhythmicities and generate results more similar to those observed using an spectral wave model.

\section{ACKNOWLEDGMENTS}

The authors would like to acknowledge funding from the internal programs at CINVESTAV and UNAM IIngen and ICMyL at Puerto Morelos. Special thanks to C.P. Felipe Escalante Bolio and his team in the administration of CINVESTAV-Merida for always helping with all required administrative procedures involved with fund management. 


\section{REFERENCES}

Angwenyi, C. M., and L. Rydberg. 2005. Wave-driven circulation across the coral reef at Bamburi Lagoon, Kenya, Estuarine Coastal and Shelf Science (63):447-454, doi:10.1016/j.ecss. 2004.12.008.

Coronado, C., Candela, J. Iglesias-Prieto, R., Sheinbaum, J., López, M., Ocampo-Torres, F.J. 2007. On the circulation in the Puerto Morelos fringing reef lagoon. Coral Reefs (26):149-163. doi 10.1007/s00338-006-0175-9.

Gourlay, M.R.; Colleter T, G. 2005. Wave-generated flow on coral reefs - an analysis for twodimensional horizontal reef-tops with steep faces. Coastal Engineering 52: 353-387.

Hench, J. L., J. L. Leichter, and S. G. Monismith. 2008. Episodic circulation and exchange in a wave driven coral reef and lagoon system, Limnology and Oceanography, 53, 2681- 2694.

Lowe, R.J.; Falter, J.L.; Monismith, S.G.; Atkinson, M.J. 2009. A numerical study of circulation in a coastal reef-lagoon system. Journal of Geophysical Research (114)C06022, doi: 10.1029/2008JC005081.

Mendoza, E., Silva, R., Baquerizo, A. \& Losada, M.A. 2008 Quad-tree based numerical model for coastal hydrodinamics simulations. In: Ocean Engineering Research Advances. Alan I. Prescott (Ed.). Nova Publishers. Chap. 9, pp. 243 - 266. New York, USA.

Silva, R., Borthwick, A.G.L., Taylor, R.E. 2005. Numerical implementation of the harmonic modified mild-slope equation. Coastal Engineering (52): 391-407.

Silva, R., Mendoza, E. and Losada, M.A. 2006. Modelling linear wave transformation induced by dissipative structures. Regular waves. Ocean Engineering (33) 16: 2150-2173

Silva, R., Ruíz, G., Posada, G., Pérez, D., Rivillas, G., Espinal, J. \& Mendoza, E. 2008. Atlas de Clima Marítimo de la Vertiente Atlántica Mexicana. Universidad Nacional Autónoma de México. 